\title{
Literature Search and \\ Review of Research \\ Involving Radioisotopes \\ Conducted by \\ Dr. G.E. Burch \\ at Charity Hospital \\ in New Orleans, Louisiana \\ under the Auspices of \\ Tulane University \\ During the 1940s, 1950s, and 1960s
}

Prepared by

Occupational Medicine Program

Medical Sciences Division

Oak Ridge Institute for Science and Education

for

Hearings by the

Subcommittee on Investigations and Oversight

Committee on Science

U.S. House of Representatives

Rep. James A. Hayes, Chairman

New Orleans, Louisiana

July 7-8, 1994

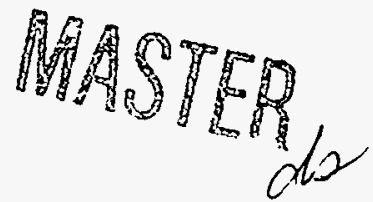




\section{DISCLAIMER}

This report was prepared as an account of work sponsored by an agency of the United States Government. Neither the United States Government nor any agency thereof, nor any of their employees, make any warranty, express or implied, or assumes any legal liability or responsibility for the accuracy, completeness, or usefulness of any information, apparatus, product, or process disclosed, or represents that its use would not infringe privately owned rights. Reference herein to any specific commercial product, process, or service by trade name, trademark, manufacturer, or otherwise does not necessarily constitute or imply its endorsement, recommendation, or favoring by the United States Government or any agency thereof. The views and opinions of authors expressed herein do not necessarily state or reflect those of the United States Government or any agency thereof. 


\section{DISCLAIMER}

Portions of this document may be illegible in electronic image products. Images are produced from the best available original document. 


\section{Table of Contents}

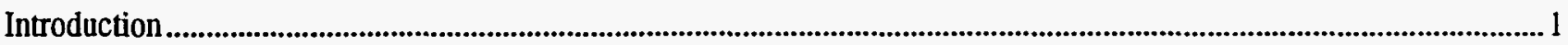

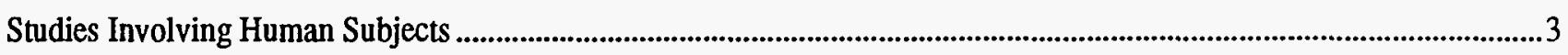

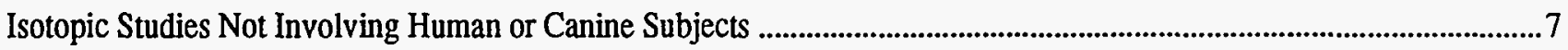

Studies Involving Dogs as Test Models .......................................................................................................................11

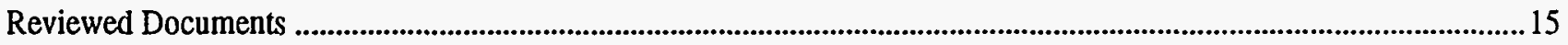

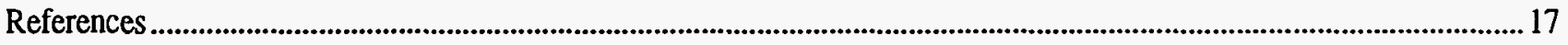

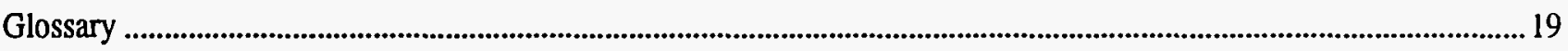




\section{Introduction}

This report presents a synopsis of research performed by Dr. G.E. Burch during the 1940s, 1950s, and 1960s at Charity Hospital in New Orleans, Louisiana. Four technical experts have reviewed twenty-seven research papers published in peer-reviewed research joumals and proceedings by Dr. Burch and his colleagues between the years 1946 and 1968. The papers were grouped prior to the review into three categories represented in this report by the following chapter titles:

- Studies Involving Human Subjects

- Isotopic Studies Not Involving Human or Canine Subjects

- Studies Involving Dogs as Test Models

The experts' reviews addressed five areas, which are presented as the following questions in each chapter:

- What, If Any, Is the Scientific Value of the Research on Which These Studies Are Based?

- Did the Research Provide Medicine with New and Useful Information?

- What Contributions Did This Research Make to Patient Care or to the Understanding of the Disease Process?

- What Was Known Medically about Matters Addressed by This Research at the Time It Was Being Conducted?

- Is There Documentation That Shows Informed Consent?

Finally, after being edited for readability and grammar, the entire document was reviewed again by a fifth technical expert, who found the reviews to be technically competent, impartial, and thorough. 



\section{Studies \\ Involving Human Subjects}

This review addresses two groups of articles or summary reports of articles that discuss the use of radioisotopes as tracers or markers to evaluate metabolism of water and a medication. The first group of eight articles to be discussed reports on the use of sodium (Na) isotopes, $\mathrm{Na}^{22}$ (3-year half-life) and $\mathrm{Na}^{24}$ (14.8-hour half-life), in determining sodium distribution as an indicator of water metabolism in normal and disease states. These articles were published from 1946 to 1949.

The second group, which consists of three articles and two summary reports from 1949 and 1950, discusses results of metabolic studies of mercurial diuretics labeled with two mercury $(\mathrm{Hg})$ isotopes, $\mathrm{Hg}^{203}$ and $\mathrm{Hg}^{206}$.

An additional article is also reviewed that discusses pathological findings in cardiac tissue from a patient who expired seven years after radiation therapy to the neck and chest to treat a malignancy.

\section{Group One: Sodium and Water Metabolism Studies}

\section{What, If Any, Is the Scientific Value of the Research on Which These Studies Are Based?}

In the early application of nuclear medicine, information relating to water distribution and mechanisms for water retention in congestive heart failure (CHF) was limited. In the 1946 study by Reaser and Burch, the use of $\mathrm{Na}^{22}$ with a longer half-life ( 3 years) than the previously investigated $\mathrm{Na}^{24}$ (14.8 hours) provided the capability to evaluate longterm phenomena associated with CHF and edema.

Additional benefit was gained by confirming generally accepted ideas about sodium and water retention variation in phases of $\mathrm{CHF}$ and the value of low-salt diets in assisting water excretion (Threefoot, Gibbons, and Burch, 1947). This information was developed from data from the two patients in the previous study.

A subsequent study on 28 subjects using $\mathrm{Na}^{24}$ established a model for compartmentalization of sodium turnover, which is rapid between plasma and intercellular fluid and slower between plasma and other structures of the body. They also demonstrated the differences in diffusion rates between normal and edematous states.

Further investigations addressed the differences in sodium excretion rates in healthy and diseased individuals; these studies indicated that excretion rate was reduced in CHF patients as compared to rates in non-CHF patients.

A paper presented in January 1948 (Threefoot, Burch, and Reaser, 1949) addresses the concept of biological halflife. The paper focuses on the utility of the biological halflife, such as its use as a physiological descriptor of the element, in determining safety factors, in measuring public and personal dose from radiation, in dose calculations, and in determining the influence of disease and new therapy evaluation.

\section{Did the Research Provide Medicine with New and Useful Information?}

To a large extent, this research validated existing concepts about water metabolism and confirmed variations between normal and disease states. The research also demonstrated similarities to conclusions in previous animal studies of sodium dynamics. New and useful information gained from the research related to the modeling of sodium turnover rates between various body compartments and the demonstration of the variation of diffusion rates between normal and abnormal (edema) conditions.

In addressing safety considerations in the use of radioisotopes, the researchers (Burch, Threefoot, and Reaser, 1948) introduced concepts of equilibrium of distribution and elimination time and their variability. These variations need to be considered in calculating safe doses from sodium radioisotopes.

Experiments demonstrated that the concentration half-life of radiosodium is increased threefold in $\mathrm{CHF}$ and fivefold in nephrotic syndrome. This contributed to the understanding of the disease process and probably influenced subsequent patient care.

Observations about the biological half-life and biological variables and subsequent modeling with consideration of theoretical physics limits provided new and useful information for modeling of other radioelements. 


\section{What Contributions Did This Research Make to Patient Care or to Understanding of the Disease Process?}

Through validation of some existing concepts of physiological and disease states, these researchers provided new tools and techniques for investigation and analysis of the effectiveness of medications and expanded knowledge to assist in the medical management of edema and CHF.

Treatment of one patient with a mercurial diuretic during one of the research efforts clearly demonstrated selective sodium excretion.

New information on sodium diffusion between various body compartments, the effect of salt intake, and differences in water metabolism in disease states assisted in patient care protocols.

\section{What Was Known Medically about Matters Addressed by This Research at the Time It Was Being Conducted?}

Much of the information prior to the use of radioisotope labeling was based on animal research and clinical observations. During this research period, even though meaningful information was being developed, "mechanisms of the retention of $\mathrm{Na}$ and water in congestive heart failure remain unknown" (Threefoot, Gibbons, and Burch, 1947). Warren and Steed (1944) reported in the Archives of Internal Medicine in a review article on Fluid Dynamics in Chronic CHF, "the common denominator of all patients with [CHF] is impaired cardiac function...and...for some reason, as yet unexplained, these patients fail to excrete salt and water in a normal fashion."

In April 1951, Danowski ("Newer Concepts of the Role of Sodium in Disease," American Journal of Medicine) cites Reaser and Burch, 1946, and Burch, Threefoot, and Reaser, 1948. When one's work is cited by peers in subsequent review articles on the matter in question, the significance of the contribution to the understanding of the matter is affirmed.

\section{Is There Documentation That Shows Informed Consent?}

No, this would not be expected in articles of this nature in this time period.
Group Two: Mercurial Diuretics Studies

\section{What, If Any, Is the Scientific Value of the Research on Which These Studies Are Based?}

Research (Threefoot, Ray, Burch, Milnor, Overman, and Gordon, 1949) was needed to understand the distribution and excretion of a mercurial diuretic (Mercuhydrin) because, although therapeutic at lower concentrations, it is toxic at high concentrations. In addition, there was a need to identify the role of diuretics in salt and water metabolism in normal and diseased states.

A second study (Overman, Gordon, and Burch, 1949) evaluated the absorption of orally administered radiomercury-tagged diuretics. Twenty-seven subjects, including five with $\mathrm{CHF}$, were studied. The substances were poorly absorbed resulting in the conclusion that oral administration of mercurial diuretics is not indicated.

In the 1950 study, Ray, Burch, Threefoot, and Kelly investigated the distribution of mercurial diuretics in the body compartments after administration in the treatment of edema. Fifty-six subjects received intravenous (IV) injections. No significant compartmentalization was observed (except bile) and rapid excretion of mercury through the kidney was confirmed.

The final report in this section was completed in 1950 (Burch, Ray, Threefoot, Kelly, and Svedberg). The research was conducted to validate findings of previous smaller pilot studies. Radiomercurial Mercuhydrin was administered intravenously or intramuscularly and excretion was monitored. The study found that the mercury cleared rapidly from the healthy subjects and was delayed in subjects with CHF. Additionally, the Mercuhyrin given intramuscularly cleared more slowly than that given intravenously, and sweating had no effect on clearance.

\section{Did the Research Provide Medicine with New and Useful Information?}

As a result of this research, researchers gained a clearer understanding of the distribution of mercury following the administration of mercurial diuretics. Orally administered medications of this nature were shown to be contraindictated and IV administration was shown to be superior to intramuscular injections for more rapid clearance. All of these findings had useful clinical application.

Three major exponential rates for the concentration-time regression curves were identified. Conclusions were: first, from the chemical mixing of the injected material; second, 
related to diffusion to more stable compartments; and third, to the excretory processes.

\section{What Contributions Did This Research Make to Patient Care or to Understanding of the Disease Process?}

As stated above, the findings from this research had useful clinical applications.

\section{What Was Known Medically about Matters Addressed by This Research at the Time It Was Being Conducted?}

There had been considerable clinical experience with mercurial diuretics. This clinical and basic science research contributed significantly to the understanding of the metabolism and efficacy of these compounds.

\section{Is There Documentation That Shows Informed Consent?}

None presented.

\section{Effects of Radiation on the Human Heart}

This report discusses an electron microscopic study of the heart of an individual who expired from CHF seven years after total thyroidectomy and $\mathrm{X}$-ray treatment for a thyroid cancer. The patient had received 4,800 rads to the thyroid and 5,200 rads to the mediastinum at the time of radiation therapy (as was consistent with radiation therapy at that time). This analysis was performed to identify subcellular effects of ionizing radiation and add to the knowledge available concerning effects of high doses of ionizing radiation on the myocardium. This patient was not involved in an experimental protocol nor were radioisotopes involved.

Although information has been presented in the literature identifying radiation-induced myocardial damage, subcellular effects had not been reported in 1968. This study indicated that after irradiation, significant changes occur at the subcellular level, including extensive disorganization of mitochondria, myofibrils, nucleus, and sarcolemma. These changes are contrasted to the ultrastructural changes seen after myocardial infarction. The authors state, "...large doses of irradiation to the mediastinum can cause damage to the myocardium that may manifest itself only months or years after the initial exposure. Cause-and-effect relationships still remain to be worked out." This article is a useful contribution to radiation biology literature. 



\section{Isotopic Studies Not Involving Human or Canine Subjects}

This review concerns 5 articles appearing over a 13-year period. Three that were published in Science describe:

- A method for separating radioactive mercury from radioactive sodium by thermal means

- A device to improve efficiency of counting accomplished with the Continuous Gas-Flow Type Counter Tube

- A means of determining deuterium oxide in water by measuring freezing point

The other two articles, which appeared in The Journal of Laboratory and Clinical Medicine and in Progress in Cardiovascular Disease, discuss, respectively, factors influencing:

- The counting of radioelements in selected liquids

- The interpretation of isotopic studies of body water and electrolytes

Although not devoid of clinical implications, these articles largely focus on physiology and procedures.

\section{What, If Any, Is the Scientific Value of the Research on Which These Studies Are Based?}

Although this research-like the overwhelming majority of scientific endeavors - produced no great breakthroughs, it represents the kind of persistent plodding that make further advances possible. The researchers appropriately sought to determine the utility and limitations inherent in the use of radioisotopes to broaden scientific understanding of physiologic phenomena, and did, therefore, add to the knowledge and techniques of the time.

The February 1949 article in Science concems the pharmacodynamics of a widely used diuretic. To investigate that drug's effects on the body, it was important to separate the organic mercurial in the medication from the sodium chloride whose excretion it promotes. A method for thermal separation is described.

The article in the May 1949 issue of Science reports on an equipment upgrade that improves counting efficiency. To facilitate the use of the Continuous Gas-Flow Type Counter Tube, a simple time-saving modification was applied.

The Science article that appeared in August 1958 offers a new approach to detection of deuterium oxide in water. To supplement the available techniques, a simple, reliable, and already available instrument was adapted for an added function. The adaptation is spelled out clearly.

The other two articles come closer to being state-of-theart (for the period) reviews. The earlier of the two discusses sample characteristics that can influence the counting of isotopic constituents. The later one addresses factors that complicate the effort to measure and the attempt to interpret findings related to body water and electrolytes.

The April 1950 article in The Journal of Laboratory and Clinical Medicine assays the influence of self-absorption, volatilization, and deliquescence on counts obtained. To avoid mismeasurements and false conclusions, it is necessary to recognize effects attributable to these factors. A series of methods are described that clarify the caveats and controls, particularly relative to the chemical environment and the method and temperature used for drying the samples.

The July 1962 article in Progress in Cardiovascular Disease highlights physical and chemical factors affecting tracer studies and presents mathematical considerations underlying their explication before discussing body water and its constituents. To use appropriately the information derived from isotopic tracer studies, one must be thoroughly aware of its limitations. The paper clearly states that while absolute values must be interpreted carefully, findings can be used to evaluate the differing rates of exchange among the various body compartments.

The foregoing would appear to support the view that on the whole the cited research did indeed add value to the scientific knowledge and techniques of its time. It also in a small way strengthened the foundations upon which later scientific understanding and skills are built. 


\section{Did the Research Provide Medicine with New and Useful Information?}

While this research did not bring to light some startling, previously unsuspected revelation, it did provide useful procedural refinements. It also supplied helpful perspectives concerning factors that may adversely affect counting measurements and results interpretation. Of the two, the latter, the matter of perspectives, has been the more consequential.

To their credit, these researchers, unlike some, were aware of factors that could influence the process. They were not to be led astray by a failure to identify and evaluate assumptions and hidden variables. For example, the July 1962 article is careful to note that the fundamental assumptions of tracer techniques are only partially supportable.

In the same article the author articulates a major. assumption made by him and by his colleagues: "It is unlikely that there are any significant radiation effects on the biologic organism from the quantities of isotopes used in tracer studies of body water and electrolytes." In support of this assumption, he cites two other authors (footnotes 1 and 2, Brannell and Quimby, respectively). He does acknowledge that "with some tracers distributed in relatively heavy concentration to specific organs and with long effective half-lives, such as isotopes of calcium or strontium in bone, there may be some effect on the organ." He indicates that there can be physical effects as well, which are due to differences in atomic weights.

That irradiation effects are unlikely to have ill effects in the circumstances cited may be a fair assumption, but it is one that deserved more evaluation. The reader is given no reason to doubt that the author was sincere in his belief that his assumptions were correct.

Once again, this research was useful for its approach and perspective.

\section{What Contributions Did This Research Make to Patient Care or to the Understanding of the Disease Process?}

Since this research concemed basic physiology rather than clinical matters, its contributions to patient care were marginal and indirect at best. However, some of the experimental work did contribute to the understanding of the disease process.

For instance, the research revealed or confirmed the wide intercompartmental variance in movement, time to equilibration, etc., of body water and electrolytes between normal and diseased organisms. Congestive heart failure, ascites, and other examples are cited. In addition, the contributions such research has made to clarification of the normal state has been of greater importance than generally recognized.

\section{What Was Known Medically about Matters Addressed by This Research at the Time It Was Being Conducted?}

While the discoveries of Becquerel and the Curies were made almost a half century before, the era of isotopes as we know it really began after World War $\Pi$. The five publications noted above, as well as the other articles reviewed in this document, grew out of research in progress from the late 1940s to the early 1960s.

At that time, doctors were beginning to understand better the mechanisms of action involved in certain disease processes and beginning to develop more scientifically based pharmaceuticals. Several antibiotics were available, whereas antipsychotics were just being introduced. Mercurial diuretics (such as the Mercuhydrin referenced in the February 1949 article) were not yet displaced by better drugs, and effective antihypertensives were newcomers to the scene.

Acute high dose radiation effects were fairly well understood, but the potential for ill effects from lower doses over a longer period was not generally appreciated. Indeed, it was rather widely assumed among both scientists and clinicians that low-dose exposures were of little consequence almost certainly in the short term and probably in the long term as well. The July 1962 article in Progress in Cardiovascular Disease voices essentially those sentiments.

Consensus was lacking as to whether there is a threshold below which risk of injury is zero. Extrapolation from effects due to high doses such as those experienced by atomic bomb survivors to those that might result from low doses led many to believe that there could surely be no consequential effects at low, low doses. Even cautious assessors of risk had to acknowledge (as they still do) that the lower the dose, the greater the uncertainty about level or likelihood of risk.

The state of knowledge about the key issues is shown in Table 1. It was against this backdrop of growing knowledge, considerable uncertainty, and sometimes unexamined assumptions that research reported in the these articles and parallel research involving human or other mammalian subjects was conducted. Whatever judgments are made of those activities should take all of these factors into account. 


\section{Is There Documentation That Shows Informed Consent?}

This question is not applicable to these studies since they did not use human subjects.

\section{Table 1. What Medicine Knew and Assumed in the Late 1940 s to Early 1960 s}

\section{Known}

IONIZING

RADIATION

INDIVIDUAL SUSCEPTIBILITY

EFFECTING

EXPOSURE
- a physical agent

- vs. chemical/biological

- energized particles or high energy rays

- capable of ionization

- variable characteristics

- low- to high-energy spectrum

- zero, poor to high-tissue penetrance

- short to long half-life

- organ specific (somewhat)

- thyroid

- bone

- etc.

- potentially hazardous

- whether natural or man-made source

- to fetus, child, specific tissues

- potentially helpful

- therapeutics

- investigation (industrial/scientific/medical)

- increased where cell tumover is rapid

- reproductive/developmental tissues

- bone marrow, GI, etc.

- somewhat dose dependent

- duration dependent

- reducible in some cases - thyroid blocking

- universal

- geophysical environment

- multiple routes

- topical, puimonary, entemal

- parental/implantation

- exposure $\neq$ contamination

- exposure possible without contamination

- contamination not possible without exposure

- subject to shielding

- e.g., with lead

- subject to monitoring

- ambient environment

- personal exposure

- dose-response related

- acutely

- chronic exposure

- high-energy agents
Assumed

Risk of harm unlikely if lowenergy agents are used.

Risk of harm unlikely if average or less susceptibility on part of target tissue, organ, or organism.

Risk of harm unlikely if low dosage. 
$-$ 


\section{Studies Involving Dogs as Test Models}

This section consists of eight reports addressing the following topics:

- Group one: pericardial transfer of radioisotopes (three articles from 1962 and 1963)

- Group two: myocardial uptake of rubidium $\left(\mathrm{Rb}^{86}\right)$ and the effect of two medications (two articles from 1957)

- Group three: distribution and decay of two radioisotopes (two articles from 1950 and 1963)

- Group four: experimental equipment (one article from 1966)

Informed consent will not be mentioned because it is not applicable to this research.

\section{Group One: Pericardial Transfer of Radioisotopes}

\section{What, If Any, Is the Scientific Value of the Research on Which These Studies Are Based?}

In two of these studies, a radioisotope was instilled in the pericardial space of the canine subjects to observe the transfer of the test elements across the intact pericardium. In the first study (Takashina, Lazzara, Cronvich, and Burch, 1962a), cadmium ( $\mathrm{Cd}^{125 \mathrm{~m}}$ ) was used because it is an important trace element in mammals, essential to certain enzyme functions. The rate of cadmium transfer was noted to be the slowest of any ions previously studied, and reasons for the slower rate were postulated. This research provided information on the permeability of the pericardium and was referenced in a 1975 study on pericardial tamponade.
The later study by Colonna, Burch, Walsh. and Darby (1963) was undertaken to better understand the biokinetics of selenium $\left(\mathrm{Se}^{75}\right)$ in a living system. They observed that selenium (an essential trace element) migrated from the pericardial space to a variety of organ tissues by an undetermined mechanism, and indicated that selenium had a ubiquitous distribution in the body. The rationale for instilling selenium in the pericardium is unclear because selenium is normally taken into the body by ingestion. This research has only been cited once since its publication, and although conducted in a scientifically valid way, its contribution to subsequent research has been minimal.

The third study (Takashina, Lazzara, Cronvich, and Burch, 1962b) investigated the transfer of fluid and electrolytes across pericardial membranes that had been removed from dogs and thus was an in vivo study; the above studies were done in vitro. The researchers established membrane transfer coefficients $(\mathrm{k})$ in vitro for deuterium oxide $\left(\mathrm{D}_{2} \mathrm{O}\right)$, hydrogen $\left(\mathrm{H}^{3}\right)$, chlorine $\left(\mathrm{Cl}^{36}\right)$, sodium $\left(\mathrm{Na}^{22}\right)$, and magnesium $\left(\mathrm{Mg}^{28}\right)$; these coefficients were compared with known in vivo values. The $k$ values for this in vitro model were higher than the in vivo values, suggesting some membrane differences in vitro versus the living animal. This research was performed in a scientifically valid way and provided new information on the movement of ions and water across the pericardium.

\section{Did the Research Provide Medicine with New and Useful Information?}

The research with cadmium provided a technique for use in subsequent studies. Although the selenium studies provided information on the distribution of selenium in dog tissues, other studies performed soon after provided more pertinent information on the behavior of selenium after ingestion or intravenous administration.

The third report provided new information on the water and ion permeability of the pericardium and provided useful background information.

\section{What Contributions Did This Research Make to Patient Care or to Understanding of the Disease Process?}

Although there is no direct correlation between this research and patient care, the developed information expanded existing knowledge about the pericardial membrane and assisted subsequent medical understanding of pericardial effusion and tamponade. 


\section{What Was Known Medically about Matters Addressed by This Research at the Time It Was Being Conducted?}

The role of selenium and cadmium as essential trace elements was known at the time of this research; therefore, the research addressing pericardial diffusion was of some value.

Because information concerning the movement of various ions and water across the pericardium was limited, the third study discussed was useful.

Group Two: Myocardial Uptake of Rubidium $\left(R b^{86}\right)$ and the Effect of Two Medications

\section{What, If Any, Is the Scientific Value of the Research on Which These Studies Are Based?}

Both of these studies, authored by Love and Burch (1957), evaluate the myocardial uptake of rubidium $\left(\mathrm{Rb}^{86}\right)$. Rubidium was considered to be metabolically similar to potassium, and canine research was considered appropriate before human research to attempt to evaluate the rate of uptake and concentration of potassium in heart disease. In these experiments, 1-norepinephrine was used to increase coronary blood flow, and Pitressin ${ }^{\circledR}$ was used to reduce it. Quantification of potassium $(\mathrm{K})$ was based on a derived $\mathrm{Rb}^{86} / \mathrm{K}$ ratio calculated from prior measurements of potassium and rubidium in plasma and myocardial tissue.

The study revealed greater turnover of rubidium and potassium by the left ventricle when compared to the turnover by the right ventricle, as well as differences in clearance rates in inner and outer ventricular walls. This clearance was increased in all myocardial regions by administration of l-norepinephrine and was reduced by infusion of Pitressin ${ }^{\circledR}$.

These studies used sound scientific methods and yielded valid scientific results that have been reproduced in other studies in the literature.

\section{Did the Research Provide Medicine with New and Useful Information?}

These studies were important in developing techniques to measure regional blood flow and potassium distribution. By demonstrating that blood flow limits the rate at which the rubidium is cleared from the system, the authors developed a new method for determining blood flow distribution. This study is routinely cited as the first study to use diffusible indicators to estimate blood flow to the subendocardial and epicardial regions of the heart.

The methodology report has been referenced many times and appears to set the framework for future nuclear medicine studies in measuring blood flow.

\section{What Contributions Did This Research Make to Patient Care or to Understanding of the Disease Process?}

These research efforts have contributed significantly to improved patient care. The two articles combined have been cited more than 140 times in the literature. They paved the way for nuclear medicine applications such as thallium scans for detecting coronary artery disease. These studies also contributed to the development of techniques to study myocardial blood flow, to evaluate the reaction of the myocardium to stressors such as hypotension and exercise, and to measure response to medications.

\section{What Was Known Medically about Matters Addressed by This Research at the Time It Was Being Conducted?}

These studies confirmed clinical impressions of cardiac function and response to medication. They were the first to validate myocardial blood flow distribution and to demonstrate potassium transfer.

\section{Group Three: Distribution and Decay of Two Radioisotopes}

\section{What, If Any, Is the Scientific Value of the Research on Which These Studies Are Based?}

The first article (Burch, Threefoot, and Ray, 1950) was directed at studying the metabolism of a long-life chlorine isotope $\left(\mathrm{Cl}^{36}\right)$ in animals before its use in humans, and publishing the implications the results might have on knowledge of electrolyte metabolism and "the importance of these observations in atomic warfare."

This study determined that one-half of all chloride in the body passed in and out of the serum each minute and onehalf the entire body store of chloride is renewed every 2.5 to 3.5 days in the normal dog. The authors' impression that as much as $3 / 7$ of total body chloride was contained in intracellular fluid was not confirmed in subsequent literature, which determined that chloride is largely 
excluded from the intracellular compartment. This error did not diminish the importance of the study.

The paper by Lazzara et al. (June 1963) discussed their research in the metabolism of magnesium $\left(\mathrm{Mg}^{28}\right)$ after it first became available in 1961. This study provided basic information concerning the kinetics of magnesium in dogs and served as a precursor for subsequent studies dealing with the importance of magnesium in coronary artery disease and cardiac arrhytmias, as well as the consequences of magnesium deficiency in cardiac disease.

\section{Did the Research Provide Medicine with New and Useful Information?}

Both studies were valuable in stimulating further research in their specific areas. The study protocols were useful as a model for later studies.

\section{What Contributions Did This Research Make to Patient Care or to Understanding of the Disease Process?}

Information on chloride biokinetics and distribution in the body contributed to the understanding of salt and water balance (first article). This research has been cited 47 times in subsequent articles and has important applications in human studies of heart failure and hypertension.

The magnesium research is valuable in that it provided the preliminary information that assisted in later determinations of magnesium's role in cardiac disease. This study has been cited 14 times in the peer-reviewed literature and is considered a useful contribution.

\section{What Was Known Medically about Matters Addressed by This Research at the Time It Was Being Conducted?}

This basic research was original in terms of the investigations being performed and helped validate existing clinical information.

At the time of the chloride research, the volume of the extracellular fluid compartment was already known; however, the research effort helped to begin refining techniques to study sodium and chloride distribution and metabolism.
Group Four: Experimental Equipment

\section{What, If Any, Is the Scientific Value of the Research on Which These Studies Are Based?}

The study by Threefoot (1966) discussed the proposed design of an "on-line" scintillator crystal that could provide prolonged, continuous monitoring and recording of radioactivity from either veins or arteries of living animals for uptake and turnover studies or for continuous blood volume determinations. A specific experiment was not conducted.

Potential concerns identified by others were related to potential for infection and clot formation. It was suggested that this design would be useful for analysis of urinary excretion.

\section{Did the Research Provide Medicine with New and Useful Information?}

The proposed method has several advantages compared to the existing requirement for multiple blood samplings:

- Time and effort for collecting and preparing multiple samples for counting could be avoided.

- The animal's blood supply would not be depleted.

- Circulatory disturbances from blood removal and replacement would be minimized.

- Sampling accuracy would be improved.

- When the method is repeated, chronic blood loss would not be a risk.

\section{What Contributions Did This Research Make to Patient Care or to Understanding of the Disease Process?}

Appropriately implemented, this method could be beneficial to humans in a study or therapy situation where repetitive sampling is required. 


\section{Reviewed Documents}

${ }^{2}$ Burch, G.E., J.A. Cronvich, T. Ray, P.B. Reaser, and S.A. Threefoot. 1949. Special sample tray for the continuous gas-flow type counter tube. Science 109:516517.

${ }^{1}$ Burch, G.E., C.T. Ray, S.A.Threefoot, FJ. Kelly, and Svedberg. 1950. The urinary excretion and biological decay periods of radiomercury labeling a mercurial diuretic in normal and diseased man. Journal of Clinical Investigation 29:1131-1138.

${ }^{1}$ Burch, George, Paul Reaser, and James Cronvich. 1947. Rates of sodium tumover in normal subjects and in patients with congestive heart failure. The Journal of Laboratory and Clinical Medicine 32(10):1169-1191.

${ }^{1}$ Burch, George E., Rajindar S. Sohal, Shih-Chien Sun, Gordon C. Miller, and Harry L. Colcolough. 1968. Effects of radiation on the human heart. Archives of Internal Medicine 121:230-234.

${ }^{1}$ Burch, G.E., P.B. Reaser, and J.A. Cronvich. 1947. Rates of sodium turnover in normal subjects and in patients with congestive heart failure. The Journal of Laboratory and Clinical Medicine 32(10).

${ }^{1}$ Burch, G.E., S.A. Threefoot, J.A. Cronvich, and P. Reaser. 1948. Theoretic and experimental considerations of biologic decay periods: Studies in man with the use of $\mathrm{Na}^{22}$. In Cold Spring Harbor Symposia on Quantitative Biology, Volume XIII, 63-74.

${ }^{3}$ Burch, G.E., S.A. Threefoot, and C.T. Ray. 1950. Rates of tumover and biologic decay of chloride and chloride space in the dog determined with the long-life isotope, Cl-36. The Journal of Laboratory and Clinical Medicine 35(3):331-347.

${ }^{1}$ Burch, G.E., S.A. Threefoot, and P.B. Reaser. 1948. Some aspects of renal excretion of $\mathrm{Na}^{24}$ by normal subjects and by patients with congestive heart failure. Stanford Medical Bulletin 6(1):81-87.

${ }^{1}$ Burch, George, Sam Threefoot, and Paul Reaser. 1948. Aspects of the biologic decay periods of sodium in normal and diseased man. Science 107:91-92.

${ }^{3}$ Colonna, G., George E. Burch, John J. Walsh, and Thomas D. Darby. 1963. In vivo transfer of radioselenium, $\mathrm{Se}^{75}$, across the pericardium of dogs. Texas Report of Biology and Medicine 21:331-336.

${ }^{2}$ Kelly, Frank J., C. Thorpe Ray, S.A. Threefoot, and G.E. Burch. 1950. Influence of self-absorption, volatilzation, and deliquescence in counting of radioelements. Journal of Laboratory and Clinical Medicine 35:606-621.

${ }^{3}$ Lazzara, R., K. Hyatt, W.D. Love, J. Cronvich, and G.E. Burch. 1963. Tissue distribution, kinetics, and biologic half-life of $\mathrm{Mg}^{28}$ in the dog. American Journal of Physiology 204:1086-1094.

${ }^{3}$ Love, W.D., and G.E. Burch. 1957. Differences in the rate of $\mathrm{Rb}^{86}$ uptake by several regions of the myocardium of control dogs and dogs receiving 1-norepinephrine and Pitressin. ${ }^{\otimes}$ Journal of Clinical Investigation 36:479-484.

${ }^{3}$ Love, W.D., and G.E. Burch. 1957. A study in dogs of methods suitable for estimating the rate of myocardial uptake of $\mathrm{Rb}^{86}$ in man, and the effect of l-norepinephrine and Pitressin. ${ }^{\otimes}$ on $\mathrm{Rb}^{86}$ uptake. Journal of Clinical Investigation 36:468-478.

1Overman, William, J., William H. Gordon, Jr., and G.E. Burch. 1949. Excretion of radioactive mercury after mercurial diuretic. $\mathrm{Xxxxxx} \mathrm{x}: \mathrm{xxx}-501$.

${ }^{1}$ Ray, C.T., G.E. Burch, S.A. Threefoot, and FJ. Kelly. 1950. The distribution of radiomercury of a mercurial diuretic in some of the body fluids of man. American Journal of Medical Sciences 220:160-165.

${ }^{1}$ Ray, C.T., S.A. Threefoot, G.E. Burch, P.B. Reaser, WJ. Overman, W.H. Gordon, J.P. Milnor, and J.A. Cronvich. 1949. Regression of a radioactive mercurial diuretic from the plasma of man. Nature 163:640-641.

${ }^{1}$ Reaser, Paul B., and George E. Burch. 1946.

Radiosodium tracer studies in congestive heart failure. Proceedings of the Society for Experimental Biology and Medicine 63:543-546.

${ }^{2}$ Reaser, Paul B., and George E. Burch. 1958. Determination of deuterium oxide in water by measurement of freezing point. Science 123:415-416. 
${ }^{2}$ Reaser, P.B., G.E. Burch, S.A. Threefoot, and C.T. Ray. 1949. Thermal separation of radiomercury from radiosodium. Science 109:198.

${ }^{3}$ Takashina, Tsunekazu, Ralph Lazzara, James A. Cronvich, and George E. Burch. 1962a. Studies of rates of transfer of $\mathrm{D}_{2} \mathrm{O}, \mathrm{H}^{3}, \mathrm{Cl}^{36}, \mathrm{Na}^{22}$, and $\mathrm{Mg}^{28}$ across the isolated pericardium of dogs. Journal of Laboratory and Clinical Medicine 60(4):662-668.

${ }^{3}$ Takashina, Tsunekazu, Ralph Lazzara, James A. Cronvich, and George E. Burch. 1962b. Transfer of $\mathrm{Cd}^{115 m}$ across the pericardium of dogs. American Heart Journal 64(3):431-432.

${ }^{2}$ Threefoot, Sam A. 1962. Some factors influencing interpretation of studies of body water and electrolytes with isotopic tracers. Progress in Cardiovascular Diseases 5(1):32-54.

${ }^{3}$ Threefoot, Sam A. 1966. A shielded coil for continuous scintillation monitoring of circulating radioactivity. Investigative Radiology 1(3):184-187.

${ }^{1}$ Threefoot, S.A., C.T. Ray, G.E. Burch, Milnor, W. Overman, and W.H. Gordon. 1949. Concentration-time course in the plasma of man of radiomercury introduced as a mercurial diuretic. Journal of Clinical Investigation 28:661-670.

${ }^{1}$ Threefoot, Sam, George Burch, and Paul Reaser. 1949. The biological decay periods of sodium in normal man, in patients with congestive heart failure, and in patients with the nephrotic syndrome as determined by $\mathrm{Na}^{22}$ as the tracer. The Journal of Laboratory and Clinical Medicine 34(1):1-13.

1Threefoot, Sam, Thomas Gibbons, and George Burch. 1947. Relationship of weight, venous pressure and radiosodium $\left(\mathrm{Na}^{22}\right)$ excretion in chronic congestive heart failure. Proceedings of the Society for Experimental Biology and Medicine 66:369-372.

${ }^{1}$ This paper is reviewed in the chapter entitled Studies Involving Human Subjects.

${ }^{2}$ This paper is reviewed in the chapter entitled Isotopic Studies Not Involving Human or Canine Subjects.

${ }^{3}$ This paper is reviewed in the chapter entitled Studies Involving Dogs as Test Models. 


\section{References}

Bache, R.J., P.A. McHale, and J.C. Greenfield, Jr. 1977. Transmural myocardial perfusion during restricted coronary inflow in the awake dog. Am. J. Physiol. 232:H645-H651.

Bishop, S.P., F.C. White, and C.M. Bloor, 1976. Regional myocardial blood flow during acute myocardial infarction in the conscious dog. Circ. Res. 38(5):429-438.

Burch, G.E., and T.D. Giles. The importance of magnesium deficiency in cardiovascular disease. American Heart Journal 94(5):649-657.

Burch, G.E., S.A. Threefoot, and C.T. Ray. 1955. The rate of disappearance of $\mathrm{Rb}^{86}$ from the plasma, the biological decay rates of $R b^{86}$, and the applicability of $R b^{86}$ as a tracer of potassium in man with and without chronic congestive heart failure. J. Lab. Clin. Med. 45:371-394.

Cousins, F.B., and I.M. Caimey. 1961. Some aspects of selenium metabolism in sheep. Flust. J. Agr. Res. 12:927942.

Danowski. 1951. Newer concepts of the role of sodium in disease. American Journal of Medicine.

Domenech, R.J., and J. Goich. 1976. Effect of heart rate on regional coronary blood flow. Cardiovasc. Res. $10: 224-231$.

Downy, H.F., et al. 1975. Myocardial and total body extractions of radionubidium in anesthetized dogs. J. of App. Physiol. 38(1):31-32.

Downy, J.M., E.S. Kirk, and D.F. Cowan. 1976. The adequacy of coronary blood flow during acute hypertension. Circ. Shock 3(2):83-91.

Fisher, H.W., and N.J.H. Rothfield. 1972. A system for simultaneous measurement of arterial and venous concentrations of radioactive substances. Medical Research Engineering, pp. 24-26.
Frieden, Earl. 1984. Biochemistry of the Essential Ultratrace Elements. New York: Plenum Press, pp. 9-11.

Fuents, F., P. Chen, and K. Stroehlein. 1994.

Clinicopathological Conference: Twenty-six-year-old hispanic woman with no medical history presents with pleuritic chest pain. Circulation 89(4):1882-1889.

Gibson, A.T., and M.B. Segal. 1978. A study of the composition of pericardial fluid, with special reference to the probable mechanism of fluid formation. J. Physiol. 277:367-377.

Gould, K.L., 1991. PET perfusion imaging and nuclear cardiology. J. Nucl. Med. 32(4):579-606.

Gould, K.L., et al. 1986. Noninvasive assessment of coronary stenosis by myocardial perfusion imaging during pharmacologic coronary vasodilation; Clinical feasibility of positron cardiac imaging without a cyclotron using generator-produced rubidium-82. Journal of the American College of Cardiology 7(4):775-789.

Hevesy G., E. Hofer, and A. Krogh. 1935. The permeability of the skin of frogs to water as determined by $\mathrm{D}_{2} \mathrm{O}$ and $\mathrm{H}_{2} \mathrm{O}$. Skandinav. Archiv. Physiol. 72:199-214.

Hung, C.H., R.D. Burow, B.J. Scherlag, et al. 1986. New method for measuring myocardial blood flow by high resolution scintigraphy in the excised dog heart. J. Nucl. Med. 27:1586-1592.

Knoebel, S.B. et al., 1978. Myocardial blood flow as measured by fractional uptake of rubidium- 84 and microspheres. J. Nucl. Med. 19(9):1020-1026.

Koefoed-Johnson, V., and H.H. Ussing. 1953. The contribution of diffusion and flow to the passage of $\mathrm{D}_{2} \mathrm{O}$ through living membranes. Effect of neurohypophyseal hormone on isolated anuran skin. Acta Physiol. Scand. 28:60-76.

Lambracht, R.M., et al. 1980. Cyclotron isotopes and radiopharmaceuticals-XXIX ${ }^{81,82 m_{R}}$ b for positron emission tomography. International Journal for Applied Radiation and Isotopes 31:343-349.

Love, W.D., and G.E. Burch. 1953. A comparison of $\mathrm{K}^{42}$, $\mathrm{Rb}^{86}$, and $\mathrm{Cs}^{134}$ as tracers of potassium in the study of cation metabolism of human erythrocytes in vitro. J. Lab. Clin. Med. 41:351-362.

Love, W.D., R.B. Romney, and G.E. Burch. 1954. A comparison of the distribution of potassium and 
exchangeable rubidium in the organs of the dog, using rubidium. Circ. Res. 2:112-122.

Malsky, P.M., P.S. Vokonas, S.J. Paul, et al., 1977. Autographic measurement of regional blood flow in normal and ischemic myocardium. Am.J. Physiol. 232:H576-H583.

Millar, K.R. 1972. Distribution of $\mathrm{Se}^{75}$ in liver, kidney, and blood proteins of rats after intravenous injection of sodium selenite. N.Z. J. Agr. Res. 15:547-564.

Paganelli, C.V., and A.K. Solomon. 1957. The rate of exchange of tritiated water across the human red cell membrane. J. Gen. Physiol. 41:259-277.

Pegram, B.L., and V.S. Bishop. 1975. An evaluation of the pericardial sac as a safety factor during tamponade. Cardiovascular Research 9:715-721.

Ray, C.T., S.A. Threefoot, and G.E. Burch. 1955. The excretion of $\mathrm{Rb}^{86}, \mathrm{~K}^{42}$, and potassium, sodium, and chloride by man with and without congestive heart failure. J. Lab. Clin. Med. 45:408-430.

Schwarz K., and C.M. Foltz. 1957. Selenium as an integral part of factor 3 against dietary necrotic liver degeneration. Journal of the American Chemical Society 79:3292-3293.

Sjögren, A., et al. 1989. Magnesium deficiency in coronary artery disease and cardiac arrhythmias. Journal of Internal Medicine 226:213-222.

Strauss, H.W., and B. Pitt. April 1978. Evaluation of cardiac function and structure with radioactive tracer techniques. Circ. 57(4):645-654.

Swanton, R.H., and D.J. Coltart. 1978. Methods for the assessment of the effects of drugs on coronary blood flow in man. British Journal of Clinical Pharmacology 6:285295.

Warren and Steed. 1944. Fluid dynamics in chronic CHF. Archives of Internal Medicine.

Wright, P.L., and M.C. Bell. 1964. Selenium-75 metabolism in the gestating ewe and fetal lamb. J. Nutr. 84:49-57. 


\section{Glossary*}

Arrhythmia - Any variation from the normal rhythm of the heart beat.

Ascites - Effusion and accumulation of serous fluid in the abdominal cavity.

Cardiac tamponade - Acute compression of the heart that is due to effusion of the fluid into the pericardium or to the collection of blood in the pericardium from rupture of the heart or penetrating trauma.

Compartmentalization - The natural partitioning within cells due to the selectively permeable membranes that enclose each of the separate parts (mitochondria, lysosomes, Golgi complex, etc.) enabling each part to regulate its own contents.

Deliquescence - The process of undergoing gradual dissolutions and liquefaction by the attraction and absorption of moisture from the air.

Deuterium - The isotope of the element hydrogen with one neutron and one proton in the nucleus.

Edema - The presence of abnormally large amounts of fluid in the intercellular tissue spaces of the body; usually applied to demonstrable accumulation of excessive fluid in the subcutaneous tissues. Edema may be localized, due to venous or lymphatic obstruction or to increased vascular permeability, or it may be systemic due to heart failure or renal disease.

Edematous - Pertaining to or affected by edema.

Electrolyte - A chemical compound that when molten or dissolved in certain solvents, usually water, will conduct an electric current.
Epicardial - Pertaining to the layer of serous pericardium on the surface of the heart.

Equilibration - The state of being brought into equilibrium, which implies a dynamic balance in a reversible chemical reaction in which the velocities in both directions are equal.

Half-life - The average time interval required for one-half of any quantity of identical radioactive atoms to undergo radioactive decay.

Infarction - The formation of an area of coagulation necrosis in tissue due to local deficiency of blood resulting from obstruction of circulation to the area.

in vitro - Pertaining to a biological reaction taking place in an artificial apparatus.

in vivo - Pertaining to a biological reaction taking place in a living cell or organism.

Isotopic - Of or relating to isotope, one of two or more atoms having the same atomic number but different mass number.

Mediastinum - The mass of tissues and organs separating the two lungs, between the sternum in front and the vertebral column behind, and from the thoracic inlet above to the diaphragm below.

Mercurial - Of or relating to mercury; a preparation of mercury.

Myocardium - The muscular tissue of the heart wall.

Myofibrils - A muscle fibril, one of the slender threads that can be rendered visible in a muscle fiber by maceration in certain acids. (Fibril: a minute fiber or filament.)

Nephrotic syndrome - A kidney disease characterized by massive edema, excess serum proteins in the urine, abnormally low albumin content of the blood, and peculiar susceptibility to intercurrent infections.

Pericardium - The fibroserous sac that surrounds the heart and the roots of the great vessels, comprising an external layer of fibrous tissue and an inner serous layer.

* Some definitions from McGraw-Hill Dictionary of Scientific and Technical Terms, Fifth Edition, 1994 and Dorland's Illustrated Medical Dictionary, Twenty-Sixth Edition, 1981. 
Pericardial effusion - The escape of fluid into a part or tissue.

Pharmacodynamics - The study of the biochemical and physiological effects of drugs and the mechanisms of their actions, including the correlation of actions and effects of drugs with their chemical structure.

Rad - A special unit of absorbed dose, equal to energy absorption of 0.01 joule per kilogram.

Radiation dose - The total amount of ionizing radiation absorbed by material or tissues.

Radioelement - A radioactive isotope of an element; a sample consisting of one or more radioactive isotopes of an element.

Radioisotope - An isotope that is radioactive.

Sarcolemma - The delicate plasma membrane that invests every straited muscle fiber.

Serous - Pertaining to or resembling serum.

Subendocardial - Beneath the endothelial lining membrane of the cavities of the heart and the connective tissue on which it lies.

Tamponade - See cardiac tamponade.

Volatilization - The conversion of a chemical substance from a liquid or solid state to a gaseous or vapor state by the application of heat, by reducing pressure, or by a combination of these processes. 